Cahiers $d u$ MONDE RUSSE

\section{Cahiers du monde russe}

Russie - Empire russe - Union soviétique et États indépendants

$52 / 4 \mid 2011$

Varia

\title{
A propos de deux ouvrages de Julie Grandhaye
}

\section{Alexander Martin}

\section{OpenEdition \\ Journals}

Édition électronique

URL : http://journals.openedition.org/monderusse/7584

DOI : 10.4000/monderusse. 7584

ISSN : $1777-5388$

Éditeur

Éditions de l'EHESS

\section{Édition imprimée}

Date de publication : 20 décembre 2011

Pagination : 686-689

ISBN : 978-2-7132-2353-2

ISSN : $1252-6576$

\section{Référence électronique}

Alexander Martin, "A propos de deux ouvrages de Julie Grandhaye », Cahiers du monde russe [En ligne], 52/4 | 2011, mis en ligne le 28 novembre 2012, Consulté le 24 septembre 2020. URL : http:// journals.openedition.org/monderusse/7584; DOI : https://doi.org/10.4000/monderusse.7584

Ce document a été généré automatiquement le 24 septembre 2020

〔c École des hautes études en sciences sociales 


\title{
A propos de deux ouvrages de Julie Grandhaye
}

\author{
Alexander Martin
}

\section{RÉFÉRENCE}

Julie GRANDHAYE, Les Décembristes. Une génération républicaine en Russie autocratique. Paris : Publications de la Sorbonne, 2011, 445 p.

Julie GRANDHAYE, Russie : la république interdite. Le moment décembriste et ses enjeux (XVIII ${ }^{\mathrm{e}}-\mathrm{XXI}^{\mathrm{e}}$ siècles). Seyssel : Champ Vallon, 2012, 377 p.

1 Les décembristes, on croit les connaître : une confrérie héroïque de beaux jeunes officiers que la mémoire historique a figés à jamais à l'instant du soulèvement de 1825 ou au moment où, accompagnés des saintes que furent leurs épouses, ils prennent le chemin de l'exil sibérien. Julie Grandhaye nous propose de découvrir une réalité bien différente qui se cache derrière cette image d'Épinal : les racines biographiques des décembristes dans la noblesse russe ; l'évolution de leurs sociétés secrètes et de leurs idées, tant avant qu'après 1825 ; et les enjeux complexes de leurs débats.

2 Les deux livres de Julie Grandhaye, publiés presque simultanément, présentent des aspects d'un même sujet pour deux publics différents. Les Décembristes : une génération républicaine en Russie autocratique est un texte à caractère académique avec, par exemple, une discussion approfondie de l'historiographie du décembrisme. Par contre, Russie : la république interdite est destiné à un plus grand public et situe sa problématique dans des contextes plus larges, que ce soit l'héritage du XVIII ${ }^{\mathrm{e}}$ siècle russe et de l'Europe des Lumières, la démocratie contemporaine, ou les turbulences politiques en Russie après les élections législatives de décembre 2011.

3 Comme leurs titres l'indiquent, le thème central des deux ouvrages est le républicanisme des décembristes. Selon Julie Grandhaye, la république, régime représentatif fondé sur la liberté et l'égalité des citoyens, est au centre de la pensée 
politique européenne depuis la fin du XvIII ${ }^{\mathrm{e}}$ siècle, et la Russie ne s'est pas tenue à l'écart de ce mouvement. L'idée républicaine y gagne des adhérents dès le règne de Catherine II, mais l'autocratie et le servage empêchent sa pleine acceptation (les débats politiques et les réformes du système de gouvernement sous Catherine II et Alexandre $\mathrm{I}^{\mathrm{er}}$ forment le sujet de la première partie de Russie: la république interdite; le thème est de moindre importance dans Les Décembristes). Ce n'est qu'avec les décembristes que la Russie entre définitivement dans la modernité politique - non pas (comme le veut la mythologie de l'intelligentsia russe) parce que leur révolte aurait été à l'origine d'une tradition révolutionnaire spécifiquement russe, mais parce qu'ils ont été les premiers en Russie à pousser jusqu'au bout une réflexion républicaine qui est commune à toute l'Europe et qui, loin d'être utopique, forme au contraire le fondement du monde contemporain. Ce n'est pas l'acte subit du soulèvement de 1825 qui crée la rupture historique, mais le passage graduel à une vision politique qui, pour la première fois dans l'histoire russe, exclut l'autocratie.

Les deux ouvrages s'interrogent donc sur le développement de la pensée républicaine des décembristes. Après la fin des guerres contre Napoléon, les futurs décembristes ont rejoint des loges maçonniques, puis formé des organisations patriotiques et philanthropiques à caractère quasi-maçonnique - l'Union du Salut et l'Union du Bien public. Julie Grandhaye examine de près les transformations qui s'opèrent au passage d'une organisation à l'autre : par exemple, l'influence des traditions maçonnique et du carbonarisme, et l'évolution des règlements internes des différentes sociétés. Dans ces associations, la pensée politique des futurs décembristes reçut une impulsion importante. Déçus par le refus d'Alexandre $\mathrm{I}^{\mathrm{er}}$ d'entreprendre des réformes libérales, ils sont ensuite entrés dans l'illégalité avec la création des sociétés secrètes du Nord, du Sud, et des "Slaves unis ». C'est à ce moment, quand les réformes d'en haut se révèlent être une chimère, que s'engage le vrai débat sur la possibilité de la république en Russie.

5 On connaît les grandes lignes de ce débat : Murav'ëv et la Société du Nord préconisaient la monarchie constitutionnelle, Pestel' et la Société du Sud étaient partisans d'une république quasi-jacobine, et les Slaves unis rêvaient d'une fédération pan-slave. Julie Grandhaye présente une lecture détaillée des textes issus de ces débats. Les influences intellectuelles (Montesquieu, Adam Smith) ; les modèles étrangers (les États-Unis, les constitutions républicaines françaises, le Tugendbund allemand); les références historiques (Grèce antique, Rome, Russie kiévienne); les influences littéraires (néoclassicisme, ossianisme, romantisme, orientalisme); les débats sur les termes fondamentaux du projet républicain (citoyen, liberté, état, loi, constitution, nation, peuple, empire, fédération, souveraineté, propriété) - tout est examiné avec rigueur et intelligence. Nous découvrons les différents genres de textes par lesquels les décembristes ont cherché à disséminer leurs idées - les textes polémiques pour lecteurs éduqués et pour les classes inférieures, les textes littéraires, et les esquisses de constitution pour la république future. Les Décembristes: une génération républicaine en Russie autocratique nous livre aussi une étude approfondie sur la réflexion politique des anciens décembristes pendant leurs années en Sibérie et après leur retour de l'exil. La thèse centrale des deux livres, à savoir qu'on a sous-estimé l'importance de l'idée républicaine dans l'histoire du décembrisme, est démontrée de manière convaincante.

6 En plus d'une étude d'histoire des idées, les deux livres - avant tout Les Décembristes tentent de dresser un portrait collectif des participants du mouvement décembriste et 
de situer ceux-ci dans la société de leur temps. Ceci est une entreprise compliquée, et elle se heurte à deux difficultés d'ordre méthodologique.

7 La première concerne les sources. L'enjeu principal des deux livres est une analyse approfondie de la pensée des décembristes à travers une lecture de textes issus de l'élite de la société. Ces textes sont indispensables pour une histoire des idées, mais au vu de la distance qui séparait leurs auteurs de la majorité de la population, il est prudent de se méfier des jugements qu'ils portent sur les autres couches sociales. Par exemple, dire que "la population russe " éprouvait « une vive émotion» pour le soulèvement grec (Les Décembristes, p. 87), n'est-ce pas risquer de projeter les idées des élites sur tout un peuple dont les opinions nous sont inconnues? De même, si un officier décembriste, dans un régiment, a fait chanter à ses soldats une chanson révolutionnaire, peut-on en conclure avec confiance que celle-ci était «très répandue dans l'armée » (Les Décembristes, p. 162)?

8 La seconde difficulté concerne la position des décembristes au sein de la noblesse russe. L'auteur veut démontrer que le décembrisme, loin d'être le fait seulement de quelques individus héroïques, représente toute une "génération républicaine ». À cette fin, Les Décembristes présente une étude prosopographique de cent quatre membres des sociétés secrètes - leur expérience militaire, leurs études à l'étranger, etc. L'analyse statistique est minutieuse et révélatrice: par exemple, les décembristes étaient en moyenne plus âgés qu'on ne l'avait parfois pensé, et il est remarquable d'observer combien étaient frères ou cousins. Mais comment appréhender la réalité humaine que représentent ces chiffres, et quelle était la relation entre les décembristes et le reste de la noblesse ? L'expérience subjective des décembristes est étudiée principalement par le biais de biographies individuelles et l'étude des écrits des décembristes. Cette méthodologie est parfaitement adaptée pour l'histoire des idées, mais dans ce contexte différent elle présente l'inconvénient de privilégier la minorité qui a laissé des témoignages écrits, surtout les dirigeants et les intellectuels du mouvement, dont on peut se demander s'ils étaient vraiment "typiques". Quant à la thèse que les décembristes représentaient toute une génération, elle semble par moments plutôt affirmée que démontrée. Vu que des personnages conservateurs tels que Magnickij, Runič, Nesselrode et Uvarov étaient à peine plus âgés que les décembristes, il n'est pas évident que « cette génération républicaine se heurte [...] à une noblesse conservatrice et, globalement, nettement plus âgée » (Les Décembristes, p. 114). Et est-il vraiment possible de prouver que la condamnation du servage était « partagée par un tiers de la noblesse russe » (Les Décembristes, p. 151)?

9 Le portrait collectif des décembristes en tant que génération de la noblesse russe reste inachevé, me paraît-il, parce qu'il ne s'inscrit pas suffisamment dans une histoire culturelle, sémiotique ou anthropologique de la noblesse, de la Russie, et du passage de l'Europe entière de l'Ancien Régime à la modernité. Les outils d'une telle historiographie existent pourtant et ne demandent qu'à être appliqués à l'étude du décembrisme. On les retrouve dans l'article de Lotman sur « Le décembriste dans la vie quotidienne " et dans les ouvrages de Richard Wortman, Andrej Zorin, Elena Marasinova, et bien d'autres. Il est dommage que cette littérature, et les questions qu'elle soulève, soient largement absentes des deux livres présents.

10 La tentative de situer la "génération décembriste " dans le contexte général de la société russe donne donc, me semble-t-il, des résultats équivoques. Mais le centre de gravité de l'ouvrage de Julie Grandhaye n'est pas là. Ce qu'elle nous propose avant tout, 
c'est une analyse des idées du républicanisme décembriste à travers l'évolution de leurs organisations et une relecture critique d'un nombre impressionnant de leurs écrits. Dans cette entreprise-là, elle a pleinement réussi, et ses livres seront des textes essentiels pour quiconque voudra dorénavant se familiariser avec l'héritage intellectuel des décembristes. 